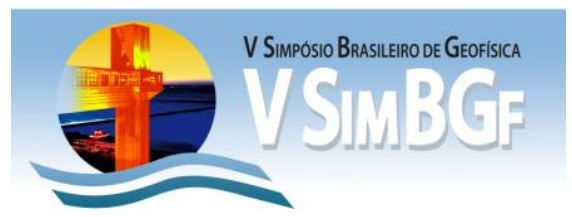

\title{
Aplicação de filtros FFT no processamento de dados aeromagnéticos: uma ferramenta para realçar feições anômalas magnéticas.
}

\author{
Renato Luiz da Silveira ${ }^{1}$, Dione Fontoura do Santos ${ }^{1}$, Mario Jesus Tomas Rosales ${ }^{1}$ \\ Universidade Federal do Pampa
}

Copyright 2012, SBGf - Sociedade Brasileira de Geofísica

Este texto foi preparado para a apresentação no V Simpósio Brasileiro de Geofísica, Salvador, 27 a 29 de novembro de 2012. Seu conteúdo foi revisado pelo Comitê Técnico do V SimBGt, mas não necessariamente representa a opinião da SBGf ou de seus associados. É proibida a reprodução total ou parcial deste material para propósitos comerciais sem prévia autorização da SBGf.

\section{Resumo}

O presente artigo consiste na aplicação de técnicas de filtragens em dados aeromagnéticos provenientes do Projeto Camaquã I, a cobertura dos dados para esta pesquisa, ocupa uma transecta na direção noroeste da Bacia do Camaquã, localizada na porção central do estado do Rio Grande do Sul, destacando-se a área territorial do município de Caçapava do Sul (RS). Foi aplicada uma metodologia convencional de tratamento de dados brutos, procedentes de levantamentos aéreos através da aplicação de diferentes filtros no domínio da freqüência, para eliminar os ruídos provocados por efeitos de linhas de vôos, e outros ruídos de natureza indesejáveis, com o objetivo de realçar feições anômalas magnéticas que virão a ser provavelmente correlacionáveis com estruturas geológicas identificadas em campo conforme o mapeamento geológico existente. Foram confeccionados mapas da anomalia magnética de intensidade total com os dados filtrados no domínio da freqüência a maneira de estabelecer uma comparação gráfica dos diferentes filtros FFT utilizados durante 0 processamento. Identificou-se que o filtro Cosseno direcional passa baixa (Cosine Filter Low Pass) foi o que melhor destacou as feições magnéticas oriundas de estruturas geológicas identificadas em campo conforme o mapeamento geológico existente.

\section{Introdução}

O trabalho consiste em uma compilação dos dados aeromagnéticos provenientes do Projeto Aerogeofísico CAMAQUÃ I (CPRM, 1974). A área que abrange a cobertura dos dados para esta pesquisa ocupa uma transecta na direção noroeste da Bacia do Camaquã, localizada na porção central do estado do Rio Grande do Sul, destacando-se a área territorial do município de Caçapava do Sul (RS). Foi aplicada uma metodologia convencional de tratamento de dados brutos procedentes de levantamentos aéreos através da aplicação de diferentes filtros no domínio da freqüência, para eliminar os ruídos provocados por efeitos de linhas de vôos, e outros ruídos de natureza indesejáveis, com o objetivo de realçar feições anômalas magnéticas que virão a ser provavelmente correlacionáveis com estruturas geológicas identificadas em campo conforme o mapeamento geológico existente.

\section{Área de estudo}

A região de estudo pertence ao Escudo-Sul-Riograndese, porção central do estado do Rio grande do Sul.

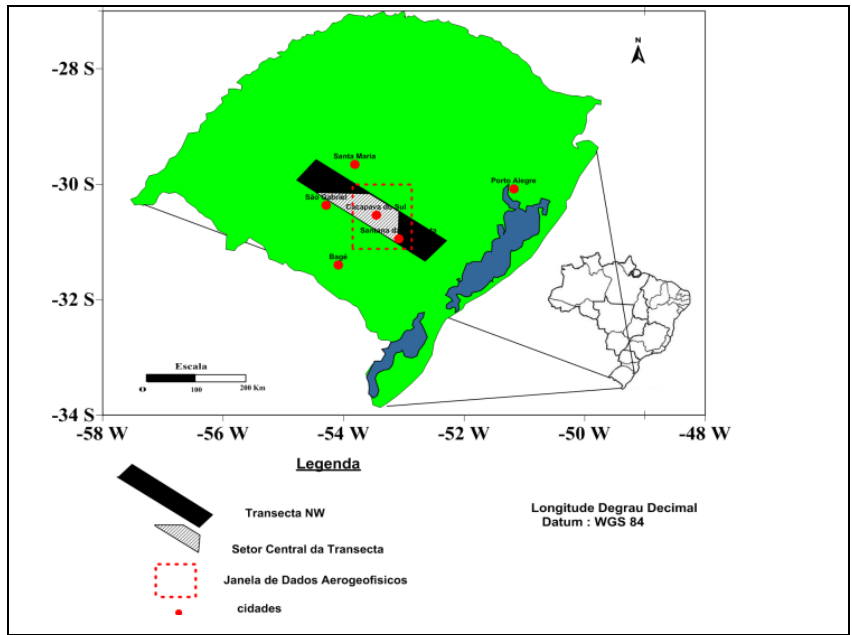

Figura 1 - mapa de localização da área de estudo que abrange a cobertura dos dados para esta pesquisa ocupa uma transecta na direção NW da Bacia do Camaquã, localizada na porção central do estado do Rio Grande do Sul, destacando-se a área territorial do município de Caçapava do Sul (RS).

\section{Arcabouço geológico}

A região abrange basicamente rochas do escudo Sul-riograndense, contexto inserido dentro da bacia do Camaquã, rochas de idade paleo-proterozóicas afetadas por intrusões granitóides. O complexo granítico Caçapava do Sul é constituído de rochas graníticas (NP3y Ca) que pode ser classificado como sienogranito, com idade em torno de $558 \mathrm{Ma}$. Esta intrusão e caracterizada sintranscorrente evidenciando uma tectônica dúctil, afetando as rochas meta-sedimentares do Complexo Vacacai $(\approx 550 \mathrm{Ma})$, composta por unidade vulcano-sedimentar constituída por xistos provenientes de metapelito, que foram deformadas e hoje margeiam todo corpo granítico. 


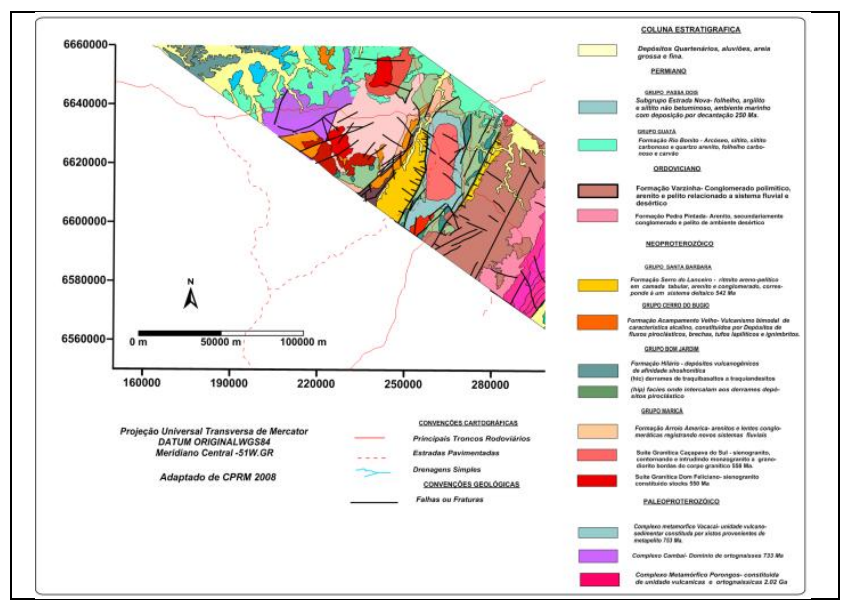

Figura 2 - mapa Geológico da porção central da Transecta (adaptado de CPRM 2006).

\section{Materiais e métodos Dados Aeromagnéticos}

Os dados altimétricos digitais utilizados neste trabalho foi O Levantamento Aerogeofísico (CPRM, 1974), segundo as suas características técnicas teve um espaçamento entre linhas de medição de $1 \mathrm{~km}$ orientadas na direção N450W com um intervalo de amostragem de 2 segundos. O equipamento utilizado foi um magnetômetro G-803 da Geometrics de procedência canadense. Os dados aeromagnéticos compilados se encontram estruturados em uma matriz de 159 linhas x 158 colunas cobrindo uma área aproximada de $12822 \mathrm{~km}^{2}$. Foram aplicados vários filtros no domínio da Frequência (FFT) tais como: Cosseno direcional passa baixa (Cosine Filter Low Pass), Gaussiano passa baixa (Gaussian Filter Low Pass), Butterworth (Butterworth Filter). Os resultados gráficos obtidos se expõem através de três perfis regionais, orientados perpendicularmente as linhas de vôos e dispostos paralelamente na área de estudo. Foram confeccionados mapas da anomalia magnética de intensidade total com os dados filtrados no domínio da freqüência a maneira de estabelecer uma comparação gráfica dos diferentes filtros FFT utilizados durante o processamento.

\section{Filtro de Cosseno Direcional}

É útil para remover/passar feições direcionais de uma malha. A função cosseno faz o filtro suavizar e, portanto, o anelamento não é problema.

\section{Filtros Butterworth}

É um excelente filtro para aplicação como passa-alta ou passa-baixa porque se pode controlar o pendente do rolamento, fixando apenas o seu número de onda central. (GEOSOFT 2005).

\section{Filtro Gaussiano}

É outro filtro suavisador usado como passa-baixa ou passa-alta.

\section{Gradiente Horizontal}

O gradiente horizontal de uma anomalia de campo potencial pode indicar mudanças laterais abruptas de propriedade física. É dado por:

$$
h(x, y)=\sqrt{\left[\left(\frac{\partial G_{z}(x, y)}{\partial x}\right)^{2}+\left(\frac{\partial G_{z}(x, y)}{\partial y}\right)^{2}\right]}
$$

Ou seja, a magnitude do gradiente horizontal é a raiz quadrada da soma dos quadrados das derivadas parciais de um campo potencial $\mathrm{Gz}(\mathrm{x}, \mathrm{y})$ em relação a x e a y.

\section{Amplitude do Sinal Analítico (ASA)}

Nabighian $(1972,1984)$ desenvolveu o conceito do sinal analítico 2-D. Uma importante característica desta técnica é a independência que ela tem com relação à direção do vetor magnetização da fonte. A amplitude do sinal analítico é simplesmente relacionada à intensidade de magnetização. Roest et al., (1992) mostraram que a amplitude (valor absoluto) do sinal analítico 3-D, em um ponto qualquer com coordenada $(x, y)$, pode ser facilmente obtido a partir de três gradientes ortogonais do campo magnético total usando a seguinte expressão:

Onde $[A(X, Y)$ é a amplitude do sinal analítico no ponto de coordenadas $(x, y)$. $T$ é a anomalia magnética de intensidade total no ponto de coordenadas $(x, y)$.

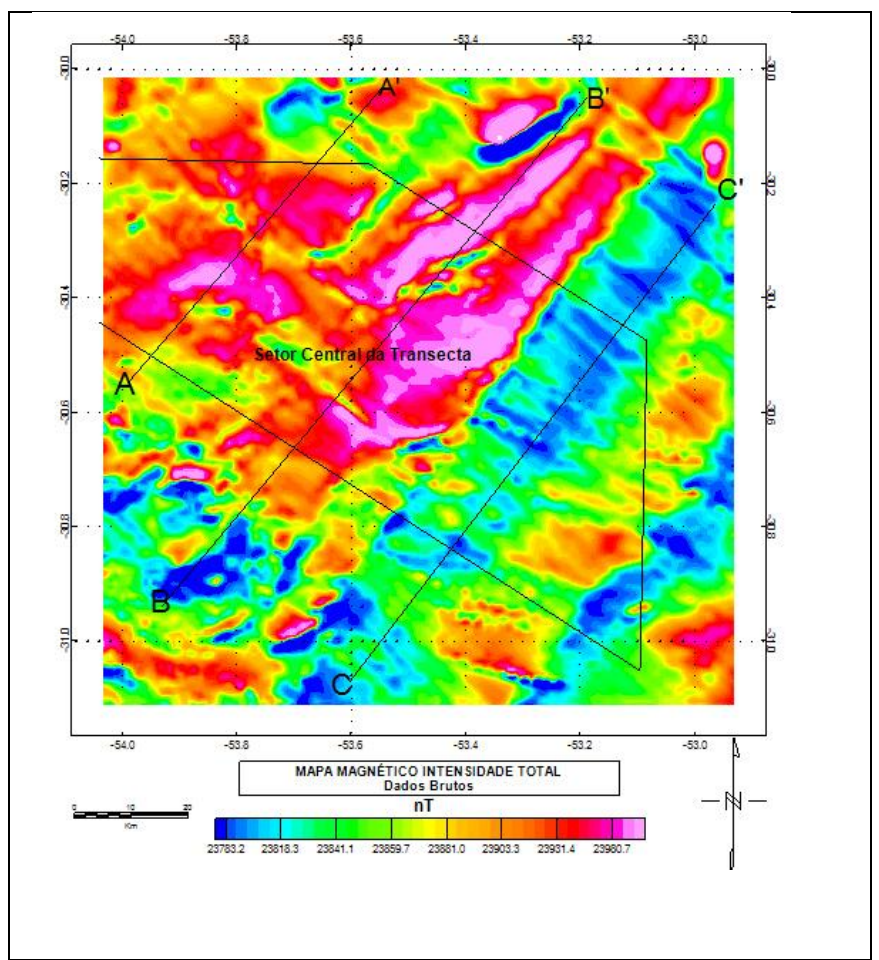

Figura 3 - mapa magnético campo Total com dados brutos, com perfis perpendiculares a direção das linhas de voôs. 


\section{Resultados}

Os resultados preliminares dos dados aeromagnéticos filtrados observados na fig. 4, através da imagem do campo anômalo total para os três filtros, Cosseno direcional passa baixa (Cosine Filter Low Pass), Gaussiano passa baixa (Gaussian Filter Low Pass), Butterworth (Butterworth Filter).

Para uma melhor analise dos filtros foram confeccionados três perfis, expresso na fig.5. sendo que o filtro cosseno direcional passa baixa foi o que melhor destacou as feições magnéticas.

A fig.6. mostra o mapa magnético de intensidade total da região de estudo com os dados magnéticos do cosseno direcional passa baixo.

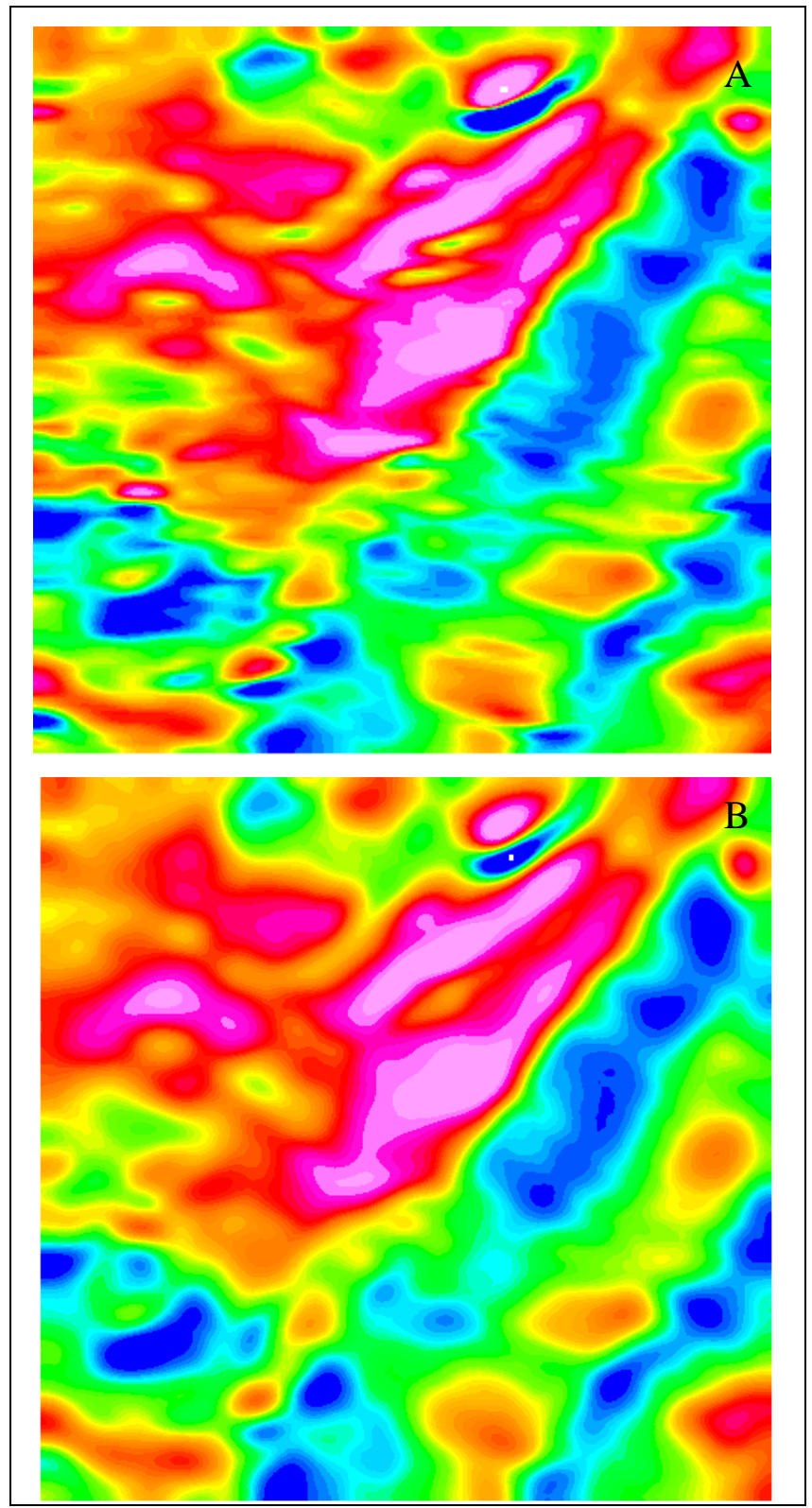

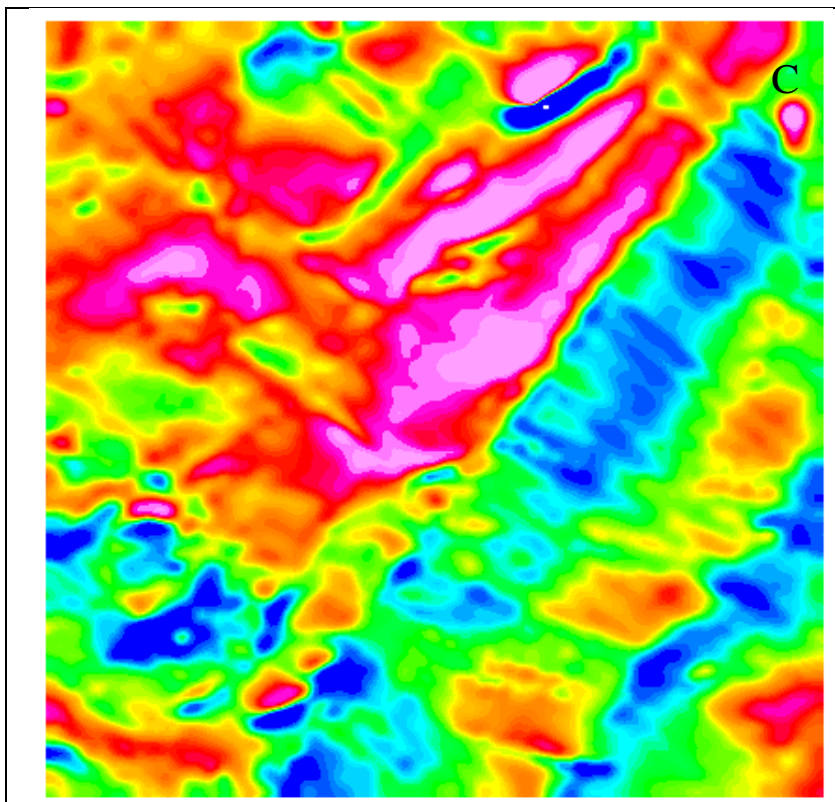

Figura 4 - imagens dos três filtros direcionais: $(A)$ Cosseno direcional passa baixa, (B) Butterwoth Gaussiano passa baixa e (C) Gaussiano passa baixa.
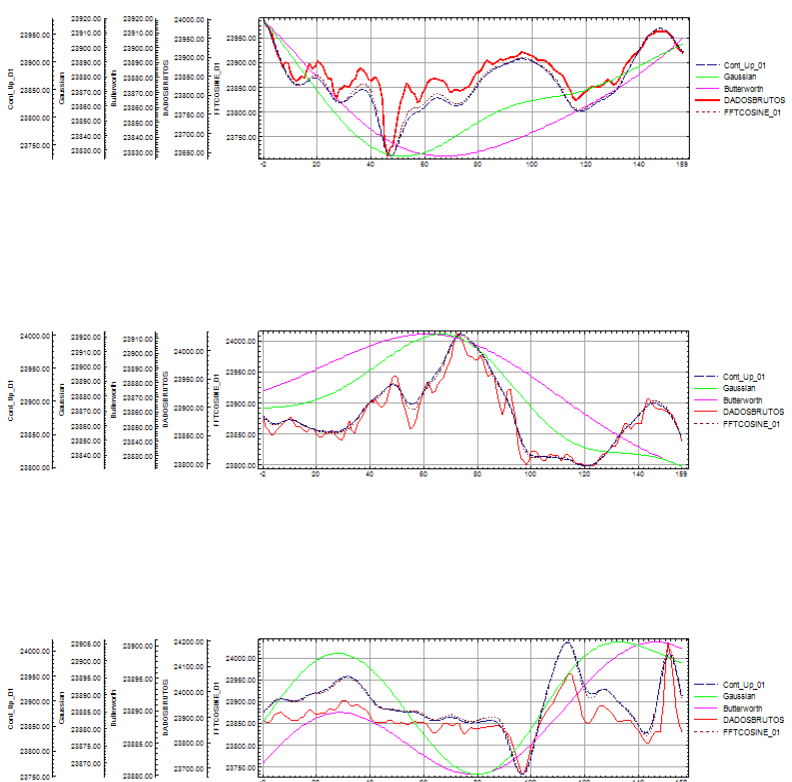

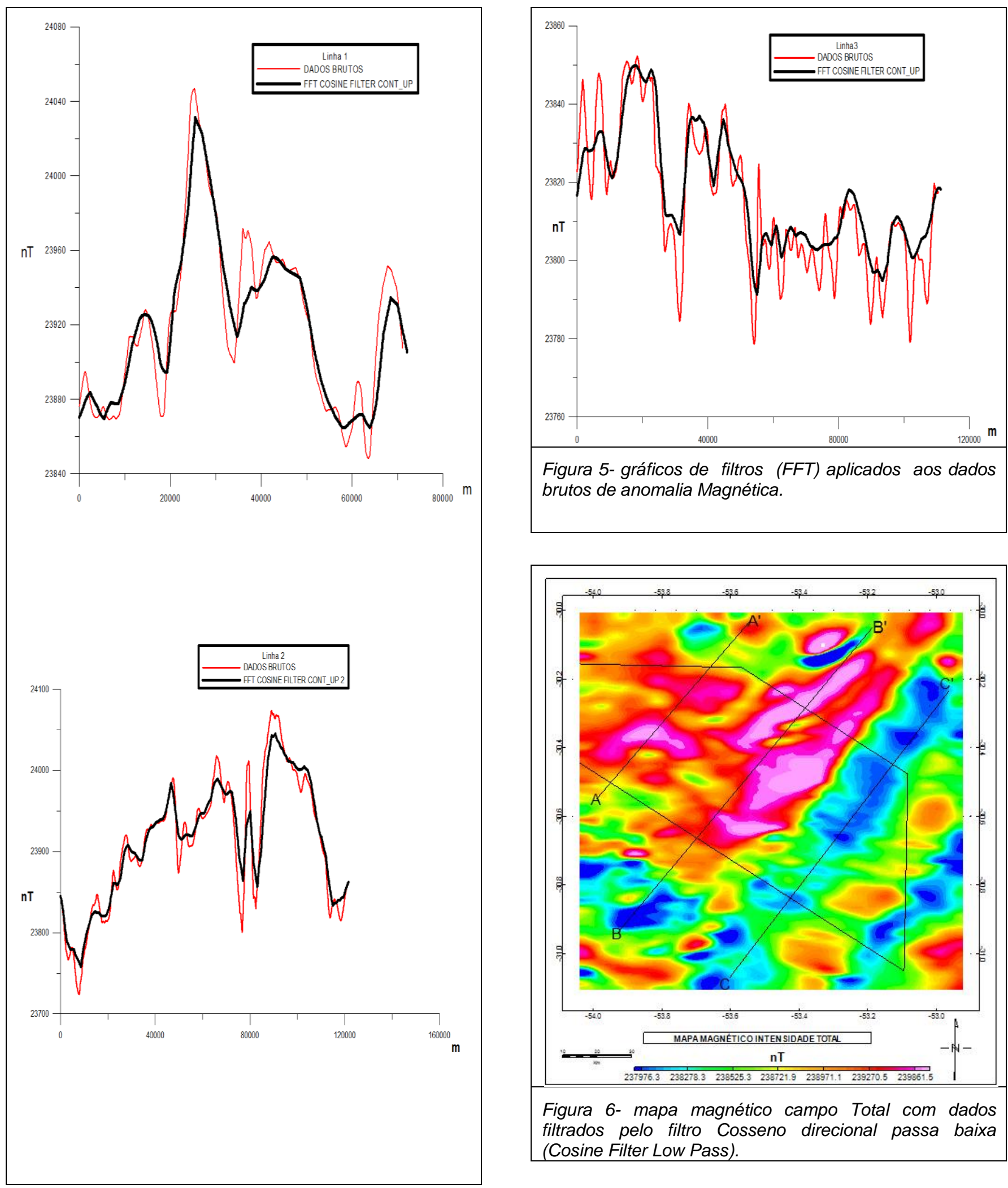

Figura 5- gráficos de filtros (FFT) aplicados aos dados brutos de anomalia Magnética.

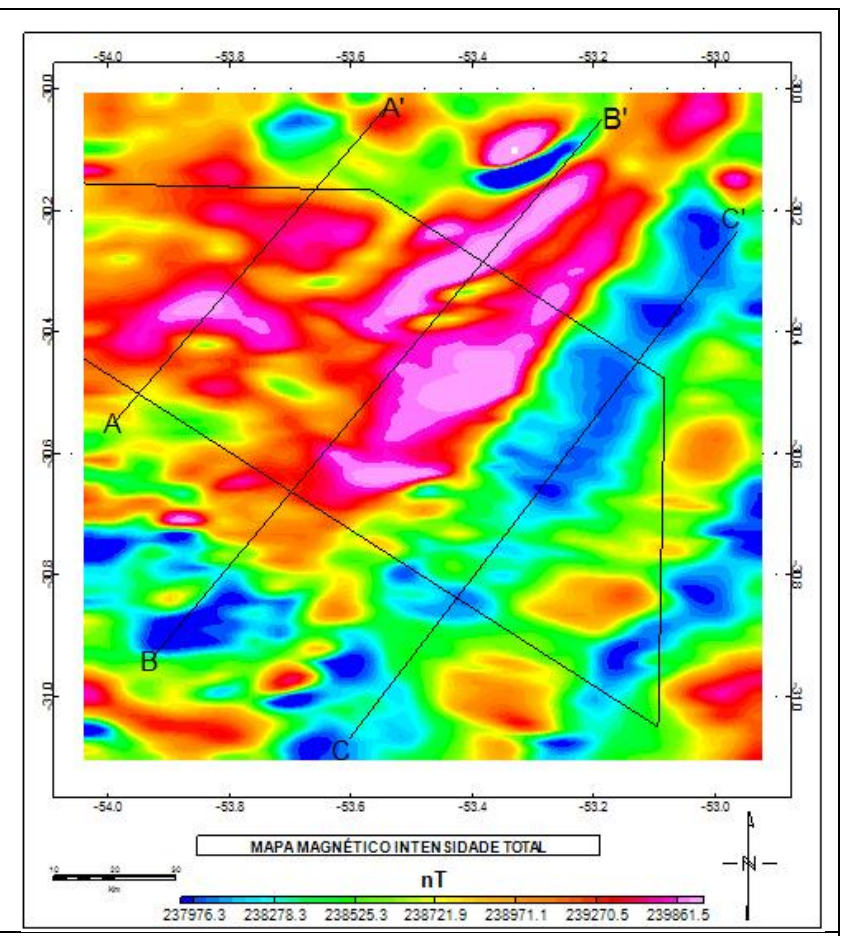

Figura 6- mapa magnético campo Total com dados filtrados pelo filtro Cosseno direcional passa baixa (Cosine Filter Low Pass). 


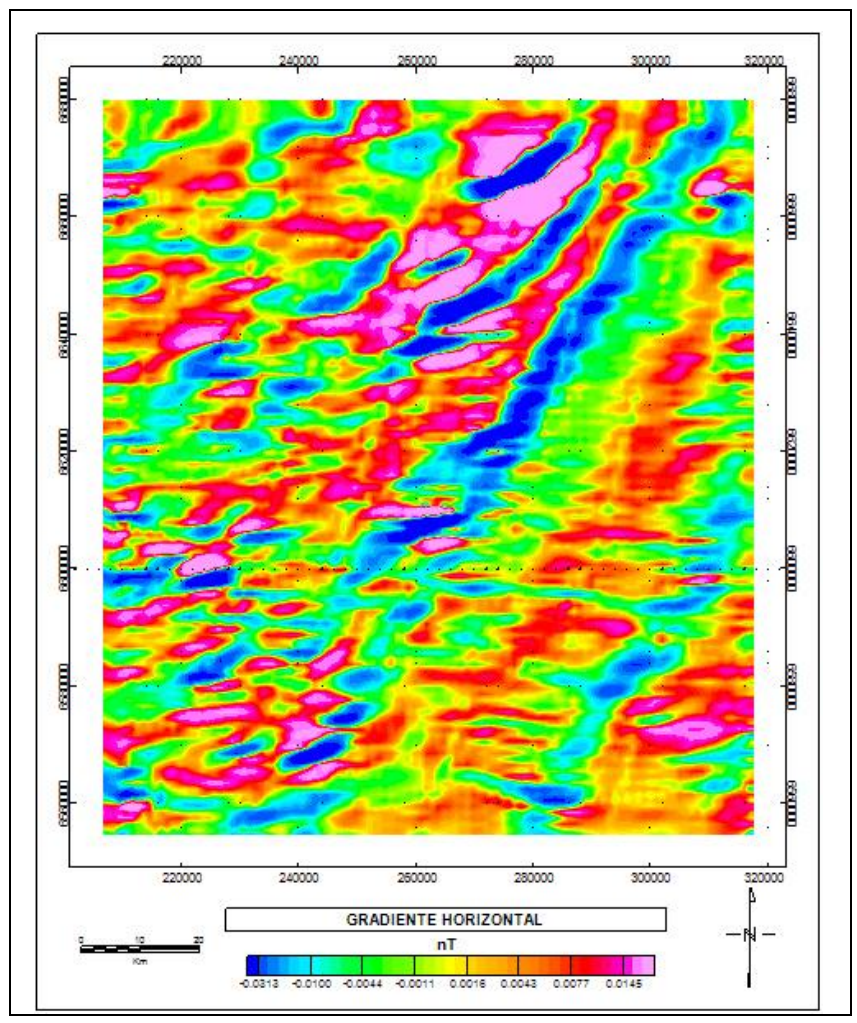

Figura 7- mapa magnético Gradiente Horizontal.

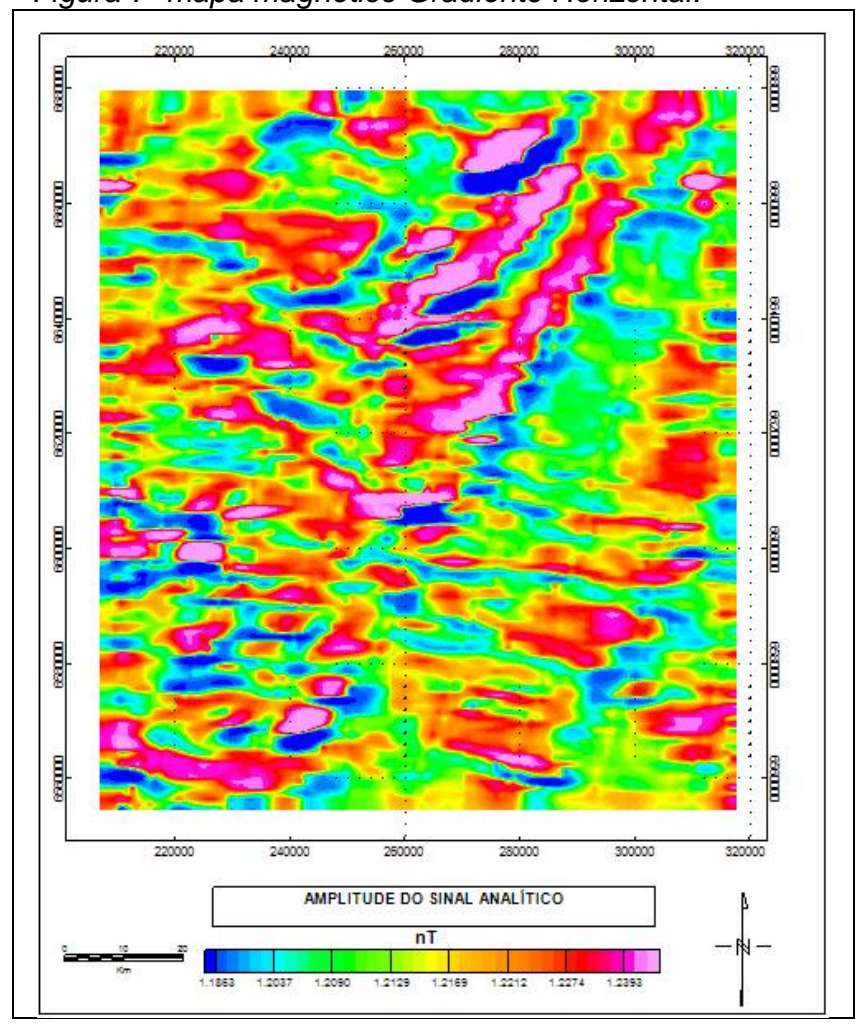

Figura 8- mapa magnético amplitude do Sinal Analítico

\section{Discussão e Conclusões}

A pesquisa demonstrou a eficiência de uma metodologia de processamento servindo de ferramenta para o apoio e esclarecimento da cartografia geológica regional.

O filtro Cosseno direcional passa baixa (Cosine Filter Low Pass) foi o que melhor destacou as feições magnéticas oriundas de estruturas geológicas identificadas em campo conforme o mapeamento geológico existente, removendo os ruidos sem afetar as informações de natureza geológica.

O trabalho faz parte de um projeto de pesquisa em andamento que tem como objetivo geral a integração e posterior interpretação de dados oriundos de Levantamentos Aerogeofísicos e Levantamentos geofísico terrestres com a finalidade de oferecer um subsídio para o mapeamento geológico regional e esclarecer questões relacionadas com a geometria da estruturação geológica da região.

\section{Referências}

CPRM - Serviço Geológico do Brasil. Mapa Geológico do Rio Grande do Sul 1:750.000. Programa de Geologia do Brasil. 2008, DVD.

GEOSOFT. 2005. Data Processing and Analysis System for Earth Science Applications. UserGuide.

JACSON, V.N.; RAMOS, V.A.; TERRY, S.A. \& ZUZEK, A.B. Projeto Aerogeofísico Camaquã, Estado do Rio Grande do Sul Porto Alegre, Texas Instruments: Convênio Departamento Nacional da Produção Mineral/Companhia de Pesquisa de Recursos Minerais/CENEN, 208 p., 1974.

NABIGHIAN MN. 1972. The analytic signal of twodimensional magnetic bodies with polygonal crosssection: Its properties and use for automated anomaly interpretation. Geophysics, 37(3): 507-517.

NABIGHIAN MN. 1974. Additional comments on the analytic signal of two-dimensional magnetic bodies with polygonal cross-section. Geophysics, 39(1): 85-92.

ROEST W.R., VERHOEF J., PILKINGTON M. 1992. Magnetic interpretation using the 3-D analytic signal. Geophysics 57, 116125. 